Pacific Journal of Mathematic 


\title{
ON AN INVERSION THEOREM FOR THE GENERAL MEHLER-FOCK TRANSFORM PAIR
}

\author{
P. Rosenthal
}

Let $P_{m}^{k}(y)$ be the Legendre function of the first kind and let $\Gamma(z)$ be the Gamma function. Then the general MehlerFock transform of complex order $k$ of a function $g(y)$ is defined by the equation

$$
\begin{aligned}
f(x)= & L_{2}(g)=\pi^{-1} x \sin h(\pi x) \Gamma\left(\frac{1}{2}-k-i x\right) \\
& \times \Gamma\left(\frac{1}{2}-k+i x\right) \int_{1}^{\infty} g(y) P_{i x-1 / 2}^{k}(y) d y,
\end{aligned}
$$

the inversion theorem states

$$
g(y)=L_{1}(f)=\int_{0}^{\infty} f(x) P_{i x-1 / 2}^{k}(y) d x .
$$

It is stated on page 416 of I. N. Sneddon's book 'The Use of Integral Transforms, (1972) that apparently a class of functions $g(y)$ for which this result is valid is not yet clearly defined. The purpose of this paper is to define a class of functions $g(y)$ as well as a class $f(x)$ and give proofs that the above inversion formula hold for these classes.

Introduction. The theorem and proofs presented in the paper are basically a generalization of those in a paper of V. Fock [4] who treated the case $k=0$, the Mehler-Fock transform. Some applications of the Mehler-Fock transform and general Mehler-Fock transform are given in [7], [8]. Tables of these transforms are given in [6].

All integrals are taken in the improper (complex) Riemann sense. $x \sim+\infty$ means $x$ positive and sufficiently large, $x \sim+1 \equiv$ sufficiently close to $1, x>1$.

THEOREM 1. Let $G$ be the class of complex valued functions such that $g \in G$ if and only if

1. $g(y)=(y-1)^{-k / 2} g_{1}(y), y>1, g_{1}(y)$ is twice differentiable and continuous for $y \geqq 1$, the real and imaginary parts of $g_{1}^{\prime \prime}(y)$ are of bounded variation on any closed and bounded interval contained in $\infty>y \geqq 1$.

2. $d^{n} g_{1} / d y^{n}=O\left(y^{-(1 / 2)-n+(k / 2)-\varepsilon}\right), y \geqq 1,1 / 4>\varepsilon>0,0 \equiv$ large order relation, $n=0,1,2$ (the case $n=0$ means $g_{1}$ ).

Then $L_{1}\left(L_{2}(g)\right)=g, y>1,|\operatorname{Re} k|<1 / 4$. 
Proof of Theorem 1.

LEMMA 1. Let

$$
\begin{aligned}
g \in G, h(t) & =\int_{0}^{t} p(t, q) d q, p=(\sinh q)^{1-k}(\cos h t-\cos h q)^{-1 / 2+k} g(\cos h q), \\
f(x) & =\int_{0}^{\infty} \cos (x t) h^{\prime}(t) d t,|\operatorname{Re} k|<\frac{1}{4} .
\end{aligned}
$$

Then

1. $f(x)=0\left(x^{-2}\right), x \sim+\infty, \int_{0}^{\infty}|f(x)| d x<\infty$.

2a. $h^{\prime}(t)$ is continuous for $t \geqq 0$.

2b. $h^{\prime}(t)$ satisfies the conditions of a Fourier inversion theorem [9, p. 13], $h^{\prime}, h^{\prime \prime}$ are both absolutely integrable over the infinite interval $\infty \geqq t \geqq 0, \lim _{t \rightarrow+0,+\infty} h=0, \lim _{t \rightarrow+\infty} h^{\prime}=0$.

3. $\int_{0}^{\infty}\left(\int_{0}^{t}|p| d q\right) d t<\infty$.

Proof of Lemma 1. Let $s=\cosh t, r=\cosh q, r=(s-1) w+1$. Then

$$
\begin{aligned}
p & =(s-1)^{(1+k) / 2}((s-1) w+2)^{-k / 2} g((s-1) w+1) c(w), \\
c(w) & =(1-w)^{-(1 / 2+k)} w^{-k / 2} .
\end{aligned}
$$

Hence there exists $c_{n}(w)$ independent of $t$ such that

$$
\begin{aligned}
\left|\frac{\partial^{n} p}{\partial t^{n}}\right| \leqq e^{-\varepsilon t}\left|c_{n}(w)\right|, t \sim+\infty, \int_{0}^{1}\left|c_{n}\right| d w<\infty, \frac{1}{4}>\varepsilon>0, n \\
=0,1,2,|\operatorname{Re} k|<\frac{1}{4} .
\end{aligned}
$$

Again by dominated convergence we conclude $d^{n} h / d t^{n}=\int_{0}^{1}\left(\partial^{n} p / \partial t^{n}\right) d w$, $\infty>t \geqq 0, n=1,2,|\operatorname{Re} k|<1 / 4$. Hence parts 2, 3 of Lemma 1 hold. We are now permitted to integrate by parts with respect to $t$ the right-hand side of the defining formula for $f(x)$ in the hypothesis of Lemma 1 to conclude $f(x)=x^{-1} F(x), F(x)=\int_{0}^{\infty} \sin (x t) h^{\prime \prime}(t) d t$. Since $h^{\prime \prime}(t)=O\left(e^{-\varepsilon t}\right), t \sim+\infty, 1 / 4>\varepsilon>0$, we conclude the real and imaginary parts of $h^{\prime \prime}(t)$ are of bounded variation in the infinite interval $\infty \geqq t \geqq 0$ (see I.P. Natanson "Theory of Functions of a Real Variable", p. 238, for definitions and theorem). This implies $F(x)=$ $O\left(x^{-1}\right), x \sim+\infty$. This completes the proof of Lemma 1.

Lemma 2. Let $g \in G$. Then 


$$
\begin{gathered}
\lim _{A \rightarrow+\infty} \int_{0}^{A>0}\left(\int_{0}^{t} \hat{f} d q\right) d t=\lim _{A \rightarrow+\infty} \int_{0}^{A}\left(\int_{q}^{A} \hat{f} d t\right) d q=\int_{0}^{\infty}\left(\int_{q}^{\infty} \hat{f} d t\right) d q, \\
\hat{f}=p \sin (x t), x \geqq 0,|\operatorname{Re} k|<\frac{1}{4} .
\end{gathered}
$$

(See Lemma 1 for the definition of $p$. )

Proof of Lemma 2. Since $g \in G$, the iterated integrals in Lemma 2 are equal for finite $A$. Part 3 of Lemma 1 implies absolute integrability of the first iterated integral in Lemma 2. Hence we satisfy Fubini's theorem which implies Lemma 2.

Lemma 3. Let

$$
F(v)=\int_{1}^{v}(v-s)^{-1 / 2+k} r d s, r=\left(s^{2}-1\right)^{-k / 2} g(s), g \in G .
$$

Then

$$
\frac{d}{d t} \int_{1}^{t}(t-v)^{-1 / 2-k} F(v) d v=\int_{1}^{t}(t-v)^{-1 / 2-k} \frac{d F}{d v} d v,|\operatorname{Re} k|<\frac{1}{4} .
$$

Proof of Lemma 3. Part 2 of Lemma 1 implies $F(v), F^{\prime}(v)$ are both continuous for $v>1, \lim _{v \rightarrow+1} F(v)=0$. Hence we satisfy a theorem (relating to the Abel integral equation) [1, p. 5] (this theorem can be modified to include singularities of the type $(x-1)^{a}, x \sim+1$, $\operatorname{Re} a>-1$, our case, see $[1$, p. 6]), which implies the conclusion of Lemma 3.

The rest of the proof of Theorem 1 consists mainly in applying the above lemmas to show that all the operations we use to show that (2) is a solution to (1) are valid.

Using the integral representation for $P_{i x-1 / 2}^{k}$ from [5, p. 165], we obtain from (2), the iterated integral,

$$
\begin{aligned}
& f(x)=a(k) x \int_{0}^{\infty}\left(\int_{t}^{\infty} p \sin (x s) d s\right) d t \\
& \text { (see Lemma } 1 \text { for the definition of } p \text { ) } \\
& a(k)=2^{1 / 2} \pi^{-3 / 2} \Gamma\left(\frac{1}{2}-k\right) \sin \left(\left(\frac{1}{2}+k\right) \pi\right), x \geqq 0,|\operatorname{Re} k|<\frac{1}{4} .
\end{aligned}
$$

(We note (3) is valid by Lemma 2.)

We now apply to the right-hand side of (3) the following operations in this order,

1. integration over a triangular domain (see Lemma 2),

2. integration by parts with respect to $s$,

3. the Fourier cosine transform.

Since operations $1,2,3$ are now permissible by Lemmas $1,2(g \in G)$, 
we obtain from (3) the valid identity

$$
\begin{aligned}
\int_{0}^{\infty} \cos (t x) f(x) d x & =a_{1}(k) \frac{d h}{d t}(\text { see Lemma } 1 \text { for definition of } h) \\
a_{1}(k) & =(2 \pi)^{-1 / 2} \Gamma\left(\frac{1}{2}-k\right) \sin \left(\left(\frac{1}{2}+k\right) \pi\right), \\
t & >0,|\operatorname{Re} k|<\frac{1}{4} .
\end{aligned}
$$

Lemma 3 implies all the operations (those indicated in Lemma 3) to show the right-hand side of (4) is a solution to an Abel integral equation are now permissible [1, p. 9]. (Again we note only real $k$ are treated on p. 9, but the theory can be extended to complex $k$, our case.) Hence applying these operations (those indicated in Lemma 3 to the right-hand side of (4), we obtain the valid identity

$$
\begin{aligned}
& g(\cosh t)=\int_{0}^{t}\left(\int_{0}^{\infty} u d x\right) d s, u=a_{2}(k)(\sinh t)^{k}(\cosh h t-\cosh s)^{-1 / 2-k} \\
& \cos (s x) f(x), a_{2}(k)=\left(2^{-1} \pi\right)^{-1 / 2}\left(\Gamma\left(\frac{1}{2}-k\right)\right)^{-1}, t>0,|\operatorname{Re} k|<\frac{1}{4} .
\end{aligned}
$$

Interchanging the order of integration of the iterated integral on the right-hand side of (5) (which is now permissible by part 1 of Lemma 1), then using the integral representation for $P_{i x-1 / 2}^{k}$ from [2, p. 156], we obtain the valid identity $L_{1}\left(L_{2}(g)\right)=g, t>0,|\operatorname{Re} k|<$ $1 / 4$. This completes the proof of Theorem 1 .

CoROLLARY 1. Let $g_{1}, g_{2} \in G$ such that $L_{2}\left(g_{1}\right)=L_{2}\left(g_{2}\right)$, then $g_{1}(t)=$ $g_{2}(t), t>0,|\operatorname{Re} k|<1 / 4$.

Proof. Let $u=g_{1}-g_{2}$. Then $u \in G$. Hence $L_{2}(u)=0$ by linearity of $L_{2}$. Hence $f(x)$ (of (3)) $=0, x \geqq 0$. We then obtain from (5) the conclusion of Corollary 1.

THEOREM 2. Let $F$ be the class of real valued functions such that $f \in F$ if and only if

1. $f(x)=x^{2} f_{1}(x), f_{1}^{\prime}(x)$ is continuous for $x \geqq 0$, and of bounded variation on any closed and bounded interval contained in $\infty>x \geqq 0$.

2. $f, f^{\prime}=O\left(x^{-1-\varepsilon}\right), x \sim+\infty, \varepsilon>0$. Then $L_{2}\left(L_{1}(f)\right)=f, x \geqq 0,|\operatorname{Re} k|<1 / 2$.

Proof of Theorem 2.

Lemma 4. Let $f \in F, g=L_{1}(f)$, then

1. $\int_{1}^{A}|g(x)| d y$ exists for any $A>1$. 
2. $g=0\left(\left(\cosh ^{-1} y\right)^{-2}\left(y^{2}-1\right)^{-1 / 4}\right), y \sim+\infty$, providing $|\operatorname{Re} k|<1 / 2$.

Proof of Lemma 4. From formula 26 [2, p. 129],

(a) $P_{i x-1 / 2}^{k}(\cos h t)=(2 \pi \sin h t)^{-1 / 2}\left(e^{-i t x} f_{1}+e^{i t x} f_{2}\right)$,

$$
\begin{aligned}
& f_{1}=\frac{\Gamma(-i x)}{\Gamma\left(\frac{1}{2}-k-i x\right)} f_{3}, f_{3}=F\left(\frac{1}{2}+k, \frac{1}{2}-k, 1+i x ;-\frac{1}{2} e^{-t} \cos h t\right), \\
& f_{2}(x)=f_{1}(-x), F(a, b, c ; z)=M \int_{0}^{1} w d s, w=s^{b-1}(1-s)^{c-b-1}(1-z s)^{-a},
\end{aligned}
$$

$\operatorname{Re} b, \operatorname{Re}(c-b)>0,|z|<1, M$ independent of $z[2$, p. 59].

(b) $z^{b-a}(\Gamma(z+a) / \Gamma(z+b)) \sim a_{1}+a_{2} z^{-1}+\cdots$ (an asymptotic series), $|z| \sim+\infty$ uniformly for $|\arg z| \leqq \pi-\varepsilon, \pi / 2>\varepsilon>0$ [2, p. 47], so differentiation of the right-hand side of $(b)$ is permissible [3, p. 21]. From (a) we conclude $(1+x)^{-1 / 2+k} f_{3}^{\prime}(x),(1+x)^{-1 / 2+k} f_{3}^{\prime \prime}(x)$ are uniformly bounded for $x \geqq 0$ and $t \geqq 1$, providing $|\operatorname{Re} k|<1 / 2$. In (1) we now use the integral representation from (a), then integrate by parts with respect to $x$, which is permissible $(f \in F)$ to conclude $g^{(j)}(y)=\left(\cosh { }^{-1} y\right)^{-1}\left(y^{2}-1\right)^{-1 / 4} \int_{0}^{\infty} e^{ \pm i t x} c^{(j)}(y, x, k) d x, y \geqq 2,|\operatorname{Re} k|<1 / 2$, further the real and imaginary parts $c^{(j)}$ are of bounded variation in $x$ on the infinite interval $\infty \geqq x \geqq 0, y \geqq 2,|\operatorname{Re} k|<1 / 2$. Hence the real and imaginary parts of $c^{(j)}$ can each be written as the difference of two monotonically decreasing functions $c_{n}^{(j)}(x), x \geqq 0$, $\lim _{x \rightarrow+\infty} c_{n}^{(j)}(x)=0$ uniformly in $y \geqq 2, c_{n}^{(j)}$ are uniformly bounded, $x \geqq$ $0, y \geqq 2,|\operatorname{Re} k|<1 / 2, n=1,2, j=1,2$, since $f(x)=O\left(x^{-1-\varepsilon}\right), x \sim+\infty$. Also $g(y)=O\left((y-1)^{-1 / 4}\right), 2>y>1,|\operatorname{Re} k|<1 / 2$, by (5) (in the proof of Theorem 1), $f \in F$. Hence Lemma 4 holds.

Lemma 5. The g of Lemma 4 implies $\int_{0}^{\infty}\left(\int_{q}^{\infty}|\hat{f}| d t\right) d q<\infty, x \geqq$ $0,|\operatorname{Re} k|<1 / 2$ (see Lemma 2 of Theorem 1 for the definition of $\hat{f}$ ).

Proof. Using the change of variable $(\cosh t-\cosh q)=(\cosh q+$ 1) $w$, we conclude $\int_{q}^{\infty}|\hat{f}| d t \leqq M(\sinh q / 2)^{-1}\left|(\sinh q)^{1-k}(\cosh q)^{k} g(\cosh q)\right|$, $q>0, x \geqq 0, M$ a constant, $|\operatorname{Re} k|<1 / 2$. Hence the conclusion of Lemma 5 follows.

The rest of the proof of Theorem 2 consists mainly in justifying in reverse order all the formulas arising from the solution of the integral equation $L_{1}(f)=g$ in the proof of Theorem 1. Hence we will point only where the rest of the proof of Theorem 2 must be modified from that of Theorem 1 . 
REMARK 1. The inversion theorem for the solution to the Abel integral equation $[1$, p. 9] appealed to in the proof of Theorem 1 has been modified to include functions which have singularities of the type $(x-1)^{a}, x \sim+1, \operatorname{Re} a>-1$. Hence this modified form of the theorem applies again to our case (see (5) in the proof of Theorem 1) since we have a singularity of this type when we use the change of variable $s=\cosh q$.

REMARK 2. Lemma 5, $f \in F$ imply the sum $\hat{h}(+\infty)-\hat{h}(+0), x \geqq$ $0,|\operatorname{Re} k|<1 / 2$, of the upper and lower limits (both are finite) (arising when one does an integration by parts, i.e., the reverse operation corresponding to the one of part 2 of (3) in the proof of Theorem 1) is zero.

REMARK 3. Lemma 5 implies the $g$ of Lemma 4 satisfies the conclusion of Lemma 2 of Theorem 1 . Hence the reverse operation of integrating over a triangular domain (see Lemma 2 of Theorem 1 ) is now permissible. Hence we conclude all the reverse formulas are valid. This completes the proof of Theorem 2 .

CoROLLARY 2. Let $f_{1}, f_{2} \in F$ such that $L_{1}\left(f_{1}\right)=L_{1}\left(f_{z}\right)$. Then $f_{1}(x)=$ $f_{2}(x), x \geqq 0,|\operatorname{Re} k|<1 / 2$.

Proof. Let $r=f_{1}-f_{2}$. Then $r \in F$. Hence by linearity $L_{1}(r)=$ 0 . Then by (3) of Theorem 1 (see also Lemma 5 of Theorem 2) we obtain the conclusion of Corollary 2.

We note in closing, using the change of variable $(\cosh t-\cosh q)=$ $(\cosh q+\cos a) s$, the integral representations for $P_{i x-1 / 2}^{k}$ in Theorem 1 and [5], we obtain a pair of reciprocal transforms

1. $g(\cosh q)=\sin a(\cosh q+\cos a)^{-3 / 2+k}(\sinh q)^{-k},|a|<\pi / 2$,

2. $f(x)=2^{1 / 2} \pi^{-1 / 2}(\Gamma(1 / 2-k))^{-1} \beta(1 / 2-k, 1) x \Gamma(1 / 2-k+i x) \Gamma(1 / 2-$ $k-i x) \sin h a x,|\operatorname{Re} k|<1 / 2$. (The case $k=0$ specializes to the example in [4].) $\beta \equiv$ Beta function. Further, $g \in G$ of Theorem 1 and $f \in$ $F$ of Theorem 2.

If in Theorem 1 , part 1 , we now assume $g_{1}$ is analytic for $y \geqq 1$, $\operatorname{Re} k<1 / 2$, in 2 we assume $n \geqq 0$ and arbitrary, then by the methods in the proofs of Theorems 1 and 2 (we use the integral representation for $P_{i x-1 / 2}^{k}$ from (5) in $\left.L_{2}\right)$, we conclude $c(k)=L_{1}\left(L_{2}(g)\right)$ is an analytic function in $k$ for $\operatorname{Re} k\langle 1 / 2, y>1$. Hence by analytic continuation, Theorem 1 and Corollary 1 are now valid for $\operatorname{Re} k<1 / 2$. 


\section{REFERENCES}

1. M. Bôcher, Integral Equations, Hafner Publishing Co., 1971.

2. A. Erdélyi et al., Higher Transcendental Functions, vol. 1, McGraw-Hill, 1953.

3. - Asymptotic Expansions, Dover Publications, 1956.

4. V. A. Fock, On the representation of an arbitrary function by an integral involving Legendre's function with a complex index, Dokl. Akad. Nauk SSSR, 39 (1943), 253-256.

5. F. Oberhettinger, Tabellen zur Fourier Transform, Springer-Verlag, 1957.

6. F. Oberhettinger and T. P. Higgins, Tables of Lebedev, Mehler and Generalized Mehler Transforms, Boeing Sci. Res. Lab., Math. Note, 246 (1961), Seattle.

7. P. Rosenthal, On a generalization of Mehler's inversion formula and some of its applications, Ph. D. thesis, Oregon State University, 1961.

8. I. N. Sneddon, The Use of Integral Transforms, McGraw-Hill, 1972.

9. E. C. Titchmarsh, Theory of Fourier Integrals, Claredon Press, 1948.

10. J. Wimp, A class of integral transforms, Proc. Edinburgh Math. Soc., 2, 14 (1964), $33-44$.

11. B. L. J. Braaksma, B. Meulenbeld, Integral transforms with generalized Legendre functions as kernels, Compositio Mathematica, vol. 18, Fasc. 3 (1967), 235-287. (See p. 247 Theorem 7 also for conditions of validity for the general Mehler-Fock transform pair.)

Received July 2, 1973. 



\section{PACIFIC JOURNAL OF MATHEMATICS}

EDITORS

RICHARD ARens (Managing Editor)

University of California

Los Angeles, California 90024

\section{R. A. Beaumont}

University of Washington

Seattle. Washington 98105

\section{J. DugundjI}

Department of Mathematics University of Southern California Los Angeles, California 90007

D. Gilbarg and J. Milgram

Stanford University

Stanford. California 94305

\section{ASSOCIATE EDITORS}
E. F. BECKENBACH
B. H. NEUMANN
F. WOLF
K. Yoshida

\section{SUPPORTING INSTITUTIONS}

\author{
UNIVERSITY OF BRITISH COLUMBIA \\ CALIFORNIA INSTITUTE OF TECHNOLOGY \\ UNIVERSITY OF CALIFORNIA \\ MONTANA STATE UNIVERSITY \\ UNIVERSITY OF NEVADA \\ NEW MEXICO STATE UNIVERSITY \\ OREGON STATE UNIVERSITY \\ UNIVERSITY OF OREGON \\ OSAKA UNIVERSITY
}

\author{
UNIVERSITY OF SOUTHERN CALIFORNIA \\ STANFORD UNIVERSITY \\ UNIVERSITY OF TOKYO \\ UNIVERSITY OF UTAH \\ WASHINGTON STATE UNIVERSITY \\ UNIVERSITY OF WASHINGTON

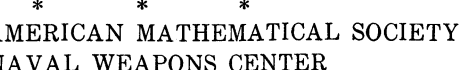

The Supporting Institutions listed above contribute to the cost of publication of this Journal, but they are not owners or publishers and have no responsibility for its content or policies.

Mathematical papers intended for publication in the Pacific Journal of Mathematics should be in typed form or offset-reproduced, (not dittoed), double spaced with large margins. Underline Greek letters in red, German in green, and script in blue. The first paragraph or two must be capable of being used separately as a synopsis of the entire paper. Items of the bibliography should not be cited there unless absolutely necessary, in which case they must be identified by author and Journal, rather than by item number. Manuscripts, in duplicate if possible, may be sent to any one of the four editors. Please classify according to the scheme of Math. Rev. Index to Vol. 39. All other communications to the editors should be addressed to the managing editor, or Elaine Barth, University of California, Los Angeles, California, 90024.

100 reprints are provided free for each article, only if page charges have been substantially paid Additional copies may be obtained at cost in multiples of 50 .

The Pacific of Journal Mathematics is issued monthly as of January 1966. Regular subscription rate: $\$ 72.00$ a year (6 Vols., 12 issues). Special rate: $\$ 36.00$ a year to individual members of supporting institutions.

Subscriptions, orders for back numbers, and changes of address should be sent to Pacific Journal of Mathematics, 103 Highland Boulevard, Berkeley, California, 94708.

\section{PUBLISHED BY PACIFIC JOURNAL OF MATHEMATICS, A NON-PROFIT CORPORATION}

Printed at Kokusai Bunken Insatsusha (International Academic Printing Co., Ltd.), 270, 3-chome Totsuka-cho. Shinjuku-ku, Tokyo 160. Japan.

Copyright (C) 1973 by Pacific Journal of Mathematics Manufactured and first issued in Japan 


\section{Pacific Journal of Mathematics}

\section{Vol. 52, No. $2 \quad$ February, 1974}

Harm Bart, Spectral properties of locally holomorphic vector-valued functions .....

J. Adrian (John) Bondy and Robert Louis Hemminger, Reconstructing infinite

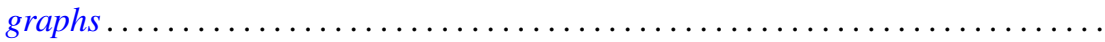

Bryan Edmund Cain and Richard J. Tondra, Biholomorphic approximation of planar

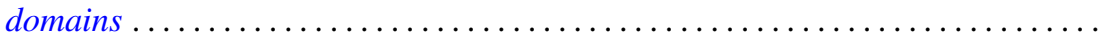

Richard Carey and Joel David Pincus, Eigenvalues of seminormal operators,

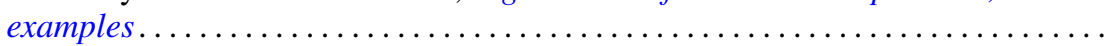

Tyrone Duncan, Absolute continuity for abstract Wiener spaces . . . . . . . . . . . . Joe Wayne Fisher and Louis Halle Rowen, An embedding of semiprime

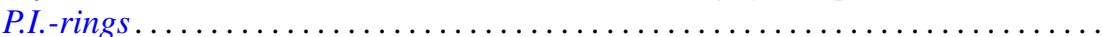

Andrew S. Geue, Precompact and collectively semi-precompact sets of semi-precompact continuous linear operators. . . . . . . . . . . . . . . .

Charles Lemuel Hagopian, Locally homeomorphic $\lambda$ connected plane continua ..... . Darald Joe Hartfiel, A study of convex sets of stochastic matrices induced by

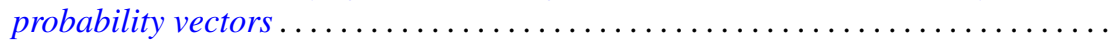

Yasunori Ishibashi, Some remarks on high order derivations $\ldots \ldots \ldots \ldots \ldots \ldots \ldots$ Donald Gordon James, Orthogonal groups of dyadic unimodular quadratic forms.

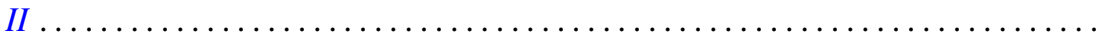

Geoffrey Thomas Jones, Projective pseudo-complemented semilattices . . . . . . . . . Darrell Conley Kent, Kelly Denis McKennon, G. Richardson and M. Schroder,

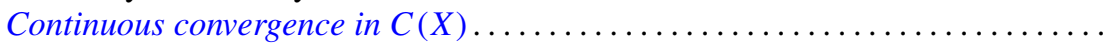

J. J. Koliha, Some convergence theorems in Banach algebras ...

Tsang Hai Kuo, Projections in the spaces of bounded linear oper

George Berry Leeman, Jr., A local estimate for typically real functions . .

475

Andrew Guy Markoe, A characterization of normal analytic spaces by the

homological codimension of the structure sheaf .........

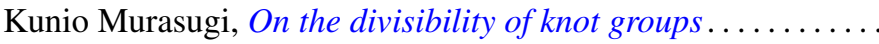

John Phillips, Perturbations of type I von Neumann algebras.

Billy E. Rhoades, Commutants of some quasi-Hausdorff matrices . .

David W. Roeder, Category theory applied to Pontryagin duality

Maxwell Alexander Rosenlicht, The nonminimality of the differential closure .

Peter Michael Rosenthal, On an inversion theorem for the general Mehler-Fock transform pair.

Alan Saleski, Stopping times for Bernoulli automorphisms

John Herman Scheuneman, Fundamental groups of compact complete locally affine complex surfaces. II. ........................

Vashishtha Narayan Singh, Reproducing kernels and operators with a cyclic vector. I. .

Peggy Strait, On the maximum and minimum of partial sums of random variables.

J. L. Brenner, Maximal ideals in the near ring of polynomials modulo 2 .

Ernst Gabor Straus, Remark on the preceding paper: "Ideals in near rings of polynomials over a field" ..........................

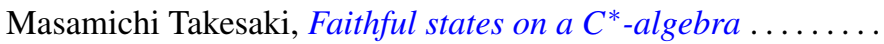

R. Michael Tanner, Some content maximizing properties of the regular simplex.

Andrew Bao-hwa Wang, An analogue of the Paley-Wiener theorem for certain

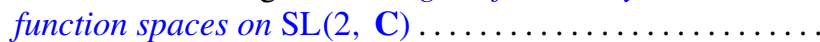

